\title{
Oxalate contents in green juice prepared using either a high-speed blender or a masticating juicer
}

\author{
Erliana Novitasari $^{1 *}$, and Geoffrey P. Savage ${ }^{2}$ \\ ${ }^{1}$ Lampung Assessment Institute for Agricultural Technology, Lampung, Indonesia \\ ${ }^{2}$ Department of Wine, Food and Molecular Biosciences, Faculty of Agriculture and Life Sciences, \\ Lincoln University, Canterbury, New Zealand
}

\begin{abstract}
Green vegetables are very beneficial for health, but sometimes it is not understood that some vegetables also contain anti-nutrients. For example, oxalic acid can be found in some green vegetables, such as spinach. Oxalic acid can be absorbed from food and as it is a toxin it has to be removed from the body via the kidneys. Under certain conditions, oxalate can combine with calcium in the kidneys forming stones which can lead to impaired kidney function. This study aims to compare two techniques for making vegetable juice, using a high-speed blender or a masticating juicer. The content of oxalic acid, calcium, $\mathrm{pH}$ and titratable acidity (TA) was measured in both juices. Total oxalic acid was measured using HPLC, calcium content was analyzed using a Coupled Plasma Optical Emission Spectrophotometer. Dry matter, $\mathrm{pH}$ and TA were measured based on AOAC methods. The highest total oxalate (OA) was found in juice made using a masticating juicer of $7638.27 \mathrm{mg} \mathrm{OA} / 100 \mathrm{~g}$ dry weight. The highest calcium content was found in the fiber fraction or in the remaining juice using the masticating juicer technique, which was $10.04 \mathrm{mg} / 100 \mathrm{~g}$ juice. Meanwhile, the TA value of the thick juice produced by the high speed blender was not significantly different from the runny juice produced by the masticating juicer. The smoothie-like green juice prepared using a highspeed blender was healthier as the soluble and insoluble oxalate extracted in the juice was lower than in the clear juice prepared using a masticating juicer.
\end{abstract}

\section{Introduction}

Green leafy vegetables mixed with several fruits processed into juice are believed to be a healthy dietary source, especially for vegans or vegetarians. Spinach, cucumber, parsley, apple, lemon, are widely used due to their content of essential amino acids, organic acids, polyunsaturated fatty acids, vitamins, and minerals [1]. Nonetheless, they also contain antinutrients such as phytic acid, lectins and oxalate which can cause a reduction of certain beneficial micronutrients in the food. Even though, the main function of these antinutrients is associated with protection of certain plants against harmful external agents, they can bring

\footnotetext{
* Corresponding author: erliana.novitasari@gmail.com
} 
some health problems to humans [2]. Oxalate which is contained in several green vegetables like spinach, parsley, chives and amaranth, in excess amounts can bind calcium and other minerals, leading to their loss in the feces. When soluble oxalates are absorbed from the intestine, they can lead to kidney stone formation as the body tries to get rid of these toxic compounds via the kidneys [3].

Oxalic acid is a common organic acid that can be found in many plants including many common vegetables, fruits, tubers, grains, and nuts. Oxalic acid with its salts and esters are called oxalates [4]. Various species of spinach have variable oxalic acid content, some cultivars of spinach contain 400-600 mg/100 g, while others range from 700-900 mg/100 g [3]. United States Department of Agriculture [4] have noted the oxalic acid contain of spinach by $970 \mathrm{mg} / 100 \mathrm{~g}$ and for celery is $190 \mathrm{mg} / 100 \mathrm{~g}$. Cucumber contains of $20 \mathrm{mg} / \mathrm{g}$ oxalic acid, while parsley contains $1700 \mathrm{mg}$ oxalate/100 g. According to Simpson et al. [5], insoluble oxalates can pass through the digestive system of humans without being absorbed and excreted in the feces. On the other hand, soluble oxalate is considered to bring significant biological problems due to its absorbtion from the digestive tract and its potential to bind to calcium and other minerals. Other studies have reported that the binding of oxalate and calcium into calcium oxalate can cause kidney stone formation [6]. It has been reported that high oxalate increase the risk of urinary stones by sequestering calcium, forming sharp calcium crystals which can cause injury to the kidney tissues and lead to inflammation [2].

There are several ways of reducing the amounts and bioavailability of oxalic acid contained in foods. Leaching the ingredient in the water can only remove the soluble oxalate. Another method is soaking combined with cooking, while blanching is considered to reduce the content of oxalic acid in spinach, sweet potato and peanuts. Fermentation has been reported as the food processing method that can also reduce the oxalate content in the foods. Otherwise, most of the beneficial nutrients will be reduced by soaking the raw foods at the same time the oxalate may be lost from the foods [3].

Fruits and vegetables are commonly consumed raw and juicing is becoming more common as many people process and or preserve them due to financial or logistic reasons. Drinking green juices prepared from raw vegetables and fruits is an effective way to improve consumption of vegetables and fruits and increase the intake of nutrients in the diet [7]. Juicing improves the digestibility and makes the fruits and vegetables easier to consume for children, the elderly or the sick. Consumers demand safe foods obtained by processing, with a preparation that takes up as little time as possible. These new habits have led to an increase in the consumption of prepared fruit and vegetable juices [8].

Previous study [9] described blending as a process which grinds up raw ingredients in the machine which has blades in the bottom of it rotating at high speed to produce the juice with a desired concistency, either a thick mixture or the smooth one depending on the speed and the duration of blending. Juicers have a different mechanism from a blender. The main purpose of juicing is to extract the juice from the raw ingredients. The process produces pure juice without pulp in it. Regular consumption of vegetables and fruits juice can reduce blood pressure and improve blood lipid profiles [7].

While juicing of fruits and vegetables is widely promoted in popular media there are limited reports on the use of different ingredients and the possible effects of these on the nutritional quality of the juices produced. An earlier study [10] investigated the use of two different processes to prepare fruit and vegetable juices which concentrated solely on the oxalate content of the juices using different levels of spinach inclusion. This study reinvestigates this earlier work concentrating on one level of spinach inclusion and carrying out further analyses of the juices produced. The objective of this experiment was to compare the oxalic acid, calcium contents, total recovery, dry matter, $\mathrm{pH}$ and total acidity of green juices prepared from green vegetables and fruits using two juicing techniques, a high-speed blender or a masticating juicer. 


\section{Materials and methods}

\subsection{Sample preparation}

Materials used in this experiments were spinach (600 g), apple (225 g), celery (168.75 g), cucumber $(168.75 \mathrm{~g})$, green pepper $(112.50 \mathrm{~g})$, red pepper $(112.50 \mathrm{~g})$, lemon $(90 \mathrm{~g})$ and parsley $(22.50 \mathrm{~g})$. These materials were obtained from a local supermarket in Lincoln, NZ. Spinach roots, green and red pepper stalks were removed before the juicing process. In addition, the seeds of apple, green and red pepper were also removed. These fruits and vegetables were cut into small pieces and processed into juice using either a high-speed blender (Vitamix 5200, Vita-Mix Corp. Cleveland, OH, USA) or a masticating juicer (Osca 9000, Dongah Industrial Co., Ltd Gyeongsangnam Do, South Korea). Each process was carried out three times. The high-speed blender produced a thick juice, while the masticasting juicer separated the juice and fiber using a low speed screw process.

\subsection{Mass balance or recovery}

All raw ingredients and equipment were weighed separately, including the containers used to collect the juice and fibre. Juice and fiber remaining in the juicers were weighed as waste. and fibre resulted by masticasting juicer were calculated as the waste. Percentage of recovery of each technique were determined using the following equation

$$
\% \text { Recovery }=\frac{\text { Total yield in containers }(g)}{\text { Total raw ingredients }(g)} \times 100 \%
$$

\subsection{Dry matter}

The empty beakers were weighed and labeled, subsequently $5 \mathrm{~g}$ of samples were accurately weighed into the empty beakers. The measurement was carried out in triplicate. Total weight of beaker and samples were recorded. All samples were stored in a desicator overnight at the room temperature. The dried samples of each sample in the beakers were then weighed and recorded. The percentage of dry matter obtained were based on the AOAC 945.15 [11] and NFTA 2.2.2.5 [12] methods, with an increased storage time in the desicator. Dry matter was presented as mean $\% \mathrm{DM} \pm \mathrm{SE}$.

\subsection{Acid and water extraction and HPLC analysis to measure oxalates}

Acid and water extractions were used to determine the total and soluble oxalates in the juice and fibre samples using the method of [13]. Three replicates of each sample (5.0 g per sample $\mathrm{x}$ three replicates) were extracted to measure total and soluble oxalate contents. 40 $\mathrm{mL}$ of $0.2 \mathrm{M} \mathrm{HCL}$ (Aristar, BDH Chemicals, Ltd., Poole, Dorset, UK) was added to volumetric flasks for the total oxalate extraction and also $40 \mathrm{~mL}$ of Nanopure II water (Barnstead International, Dubuque, Iowa, USA, $18 \mathrm{M} \Omega \mathrm{cm}$ ) was added for the extraction of soluble oxalates. All flasks were placed in an $80^{\circ} \mathrm{C}$ shaking water bath for 20 minutes. The solutions were allowed to cool to $20^{\circ} \mathrm{C}$ and then made up to $100 \mathrm{~mL}$ with $0.2 \mathrm{M} \mathrm{HCL}$ for total oxalate and Nanopure II water for soluble oxalate, respectively. Three replicates of each sample were extracted to measure total and soluble oxalate contents. $40 \mathrm{~mL}$ of $0.2 \mathrm{M}$ HCL (Aristar, BDH Chemicals, Ltd., Poole, Dorset, UK) was added to volumetric flasks for the total oxalate extraction and also $40 \mathrm{~mL}$ of Nanopure II water (Barnstead International, Dubuque, Iowa, USA, $18 \mathrm{M} \Omega \mathrm{cm}$ ) was added for the extraction of soluble oxalates. All 
flasks were placed in an $80^{\circ} \mathrm{C}$ shaking water bath for 20 minutes. The solutions were allowed to cool to $20^{\circ} \mathrm{C}$ and then made up to $100 \mathrm{~mL}$ with $0.2 \mathrm{M} \mathrm{HCL}$ for total oxalate and Nanopure II water for soluble oxalate, respectively. The extracts in the volumetric flasks were filtered through a cellulose acetate syringe filter with a pore size of $0.45 \mu \mathrm{m}$ (dismic-25cs, Advantec, California, USA) into $1 \mathrm{~mL}$ glass HPLC vials. The samples were analysed with a highperformance liquid chromatography (HPLC) system, using a $300 \mathrm{~mm} \times 7.8 \mathrm{~mm}$ Rezex ion exclusion column (Phenomenex Inc., Torrance, CA, USA) attached to a Cation-H guard column (Bio-Rad, Richmond, CA, USA) held at $25 \mathrm{oC}$. The analysis was performed by injecting $20 \mu \mathrm{L}$ of sample or standard onto the column using an aqueous solution of 25 mm sulphuric acid (HPLC grade Baker Chemicals, Phillipsburg NJ, USA) as the mobile phase, then pumped isocratically at $0.6 \mathrm{~mL} / \mathrm{min}$, with peaks detected at $210 \mathrm{~nm}$. The HPLC equipment consisted of a Shimadzu LC-10AD pump, CTO-10A column oven, SPD10Avp UV-Vis detector (Shimadzu, Kyoto, Japan) and a Waters 717 plus autosampler (Waters, Milford MA, USA).

Data acquisition and processing were undertaken using the Peak Simple Chromatography Data System (model 203) and Peak Simple software version 4.37 (SRI Instruments, Torrance CA, USA). The oxalic acid peak was identified by comparing the retention time to a standard solution and by spiking an already-filtered sample containing a known amount of oxalic acid standard. A standard curve method was used to determine the oxalate acid content of each sample. The insoluble oxalate content of each sample was calculated by the difference between the total and the soluble oxalate contents. The final data are presented as a mean of $\mathrm{mg}$ oxalic acid/100 $\mathrm{g} \mathrm{DW} \pm \mathrm{SE}$.

\subsection{Calcium analysis}

Samples were taken out of the refrigerator and thawed. They were then shaken in order to homogenize the sample. A Coupled Plasma Optical Emission Spectrophotometer was used to measure the calcium content in each sample. The calcium content was measured in triplicate. The calcium contents in the fraction of juice were presented in $\mu \mathrm{g} / \mathrm{g}$ fresh weight (FW). The final result were presented as $\mathrm{mg} / 100 \mathrm{~g} \mathrm{DM} \pm \mathrm{SE}$.

\section{6 pH and Titratable Acidity (TA)}

Homogenized samples were taken out from the refrigerator and thawed. Each sample was then stirred evenly, and the $\mathrm{pH}$ and TA were measured using a titration method based on AOAC 950.15 [14] method. The analysis was carried out on the aqueous juice and thick juice samples in triplicate from each set of recipes and the final data are presented as a mean of $\mathrm{pH}$ $\pm \mathrm{SE}$ and a mean of $\mathrm{TA} \pm \mathrm{SE}$.

\subsection{Statistical analysis}

All the data are presented as mean oxalate concentration \pm SE. Statistical analysis was carried out using Microsoft Excel followed by One Way Anova analysis with a significant level $(\alpha)$ p-value $<0.05$. Subsequently, analysis using a Two Sample t-Test was applied to determine whether the samples were significantly different or not significantly different from the others. 


\section{Results and discussion}

\subsection{Total yield recovery and dry matter}

The high-speed blender produced a thick juice, while masticasting juicer produced a clear aqueous juice and a semi-dry fiber fraction. The fiber produced by the masticasting juicer is considered to be waste and would be discarded. The mean percentage recovery and the dry matter content of the two juices are shown in Table 1.

Table 1. Percentage of total recovery and mean dry matter of two juices $(\%$ mean $\pm \mathrm{SE})$.

\begin{tabular}{|c|c|c|c|}
\hline \multirow{2}{*}{ Factors (\%) } & $\begin{array}{c}\text { High-speed } \\
\text { Blender }\end{array}$ & \multicolumn{2}{|c|}{ Masticating Juicer } \\
\cline { 2 - 4 } & Thick Juice & Clear Juice & Discarded Fibre \\
\hline Recovery & $99.40 \pm 0.02^{\mathrm{a}}$ & $74.88 \pm 0.42^{\mathrm{b}}$ & \\
\hline Dry matter & $9.57 \pm 16.60^{\mathrm{b}}$ & $7.36 \pm 5.82^{\mathrm{c}}$ & $16.17 \pm 2.70^{\mathrm{a}}$ \\
\hline
\end{tabular}

*Values in the same line with different superscript indicate significant differences $(p<0.05)$

The high-speed juicer produced a thick juice more like a smoothie while the masticating juicer produced a clear juice. The clear juice still contained a moderate level of dry matter. The recovery of juice using the high-speed blender was significantly higher $(p<0.05)$ because little material was retained or lost in the blender and no fibre was discarded during the extraction process.

\subsection{Total soluble and insoluble oxalates contents in the juice}

Total oxalate was obtained using a hot acid extraction and soluble oxalates were recovered using a hot water extraction, while insoluble oxalates were calculated from the difference between total and soluble oxalate values. The mean total, soluble and insoluble oxalates in the green juice are shown in Table 2.

Table 2. Mean total, soluble and insoluble oxalates of green juice were produced using a high-speed blender or a masticating juicer

\begin{tabular}{|c|c|c|c|}
\hline & High-speed Blender & \multicolumn{2}{|c|}{ Masticating Juicer } \\
\cline { 2 - 4 } & Thick Juice & Clear Juice & Discarded Fibre \\
\hline $\begin{array}{c}\text { Total Oxalate (mg/100 } \\
\text { g DW) }\end{array}$ & $4087.52 \pm 13.65^{\mathrm{b}}$ & $7638.27 \pm 6.17^{\mathrm{a}}$ & $3302.58 \pm 16.68^{\mathrm{c}}$ \\
\hline $\begin{array}{c}\text { Soluble Oxalate } \\
(\mathrm{mg} / 100 \text { g DW) }\end{array}$ & $2996.86 \pm 14.33^{\mathrm{b}}$ & $4124.78 \pm 13.00^{\mathrm{a}}$ & $1646.16 \pm 28.13^{\mathrm{c}}$ \\
\hline Soluble oxalate (\%) & 73.32 & 54.00 & 49.84 \\
\hline $\begin{array}{c}\text { Insoluble Oxalate } \\
\text { (mg/100 g DW) }\end{array}$ & $1090.66 \pm 19.60$ & $3513.48 \pm 28.41$ & $1656.42 \pm 14.41$ \\
\hline Insoluble oxalate (\%) & 26.68 & 46.00 & 50.16 \\
\hline
\end{tabular}

* Values in the same line with different superscripts indicate significant differences $(p<0.05)$

The oxalate content of the two juices were very high because the juice was made using a high proportion of spinach (Table 2) and it is well known that spinach leaves contain very high levels of oxalates [3]. Spinach was used as it is a commonly available leafy vegetable that is relatively inexpensive. It provides a good source of green juice, and the other ingredients are used to balance up the taste and texture of the juice. The other ingredients also provide oxalates in the mixture, but the levels found in their tissues are generally much lower [3]. 
It is interesting to note that the total, soluble and insoluble oxalate contents of the clear juice extracted by the masticating juicer are higher than the thick juice prepared by the highspeed blender. The levels are higher even though considerable amounts of oxalates are removed in the fibre fraction. The insoluble oxalate levels of the clear juice are higher than the smoothie-like juice produced by the high-speed blender. It should be noted that the clear juice produced by the masticating juice contains $46.0 \%$ insoluble oxalate compared to $26.7 \%$ in the thick juice. High levels of insoluble oxalate are of no real concern as they are not absorbed during their passage through the digestive tract.

The high levels of soluble oxalate in the clear juice are more of a concern, this is an effect caused by the removal of fibre during the masticating process. Fibre, although it contains oxalates and is removed from the mixture by the masticating process, is retained in the highspeed blender juice, so it has a diluting effect on the overall clear juice mixture. Insoluble oxalates can pass through the digestive system of humans without being absorbed and excreted in the feces. In excess amount, soluble oxalate is considered to bring significant biological problems due to its absorbtion from the digestive tract and its potential to bind to calcium and other minerals. The binding of oxalate and calcium into calcium oxalate can cause kidney stone formation [6].

\subsection{Calcium, pH, and TA}

The calcium contents of the juices made in this experiment were analyzed because oxalates can bind to several minerals, particularly calcium and less strongly to other divalent elements such as magnesium. It is interesting to note that the calcium contents of the two juices (Table 3) were statistically different $(p<0.05)$ even though they were made from the same ingredients in the same proportions. The calcium level in the discarded fraction was much higher than the juice it was separated from. This suggests that the calcium in the discarded fraction was firmly bound to the fibre fraction which would mean that the calcium in this mixture of fruits and vegetables would not be readily available in the digestive system as fibre is usually voided in the faeces undigested.

Table 3. Mean value of calcium content in $\mathrm{mg} / 100 \mathrm{~g}$ DM basis, $\mathrm{pH}$ and total titratable acidity (TA) in $\mathrm{g} / \mathrm{L}$ in the green juice $\pm \mathrm{SE}$.

\begin{tabular}{|c|c|c|c|}
\hline \multirow{2}{*}{} & $\begin{array}{c}\text { High-speed } \\
\text { Blender }\end{array}$ & \multicolumn{2}{|c|}{ Masticating Juicer } \\
\cline { 2 - 4 } & Thick Juice & Clear Juice & Discarded Fibre \\
\hline Calcium $(\mathrm{mg} / 100 \mathrm{~g}$ DW) & $3.18 \pm 31.69^{\mathrm{c}}$ & $3.36 \pm 5.89^{\mathrm{b}}$ & $10.04 \pm 12.00^{\mathrm{a}}$ \\
\hline $\mathrm{pH}$ & $4.57 \pm 0.33$ & $4.49 \pm 0.59$ & - \\
\hline $\mathrm{TA}(\mathrm{g} / \mathrm{L})$ & $4.14 \pm 4.20$ & $3.75 \pm 3.22$ & - \\
\hline
\end{tabular}

* Values in the same line with different superscripts indicate significant differences $(p<0.05)$.

The $\mathrm{pH}$ values of the two juices were similar because they were processed from the same original ingredients. Relatively low $\mathrm{pH}$ levels were obtained because apples and lemons were added to the original mix of ingredients. Addition of these ingredients would give the extracted juice a pleasant tart taste to the juices.

The titratable acidity of the two juices were similar due the same range of fruits and vegetables used to make the juices. The TA method measures the titratable acidy as citric acid but it is clear that fruits and vegetables contain a range of plant acids. For instance, apples contain high levels of malic acid. Previous study [15], measured the malic acid content of 175 varieties of apples with a mean value of $847.7 \mathrm{mg} / 100 \mathrm{ml}$ with some cultivars ranging up to $1544.9 \mathrm{mg} / 100 \mathrm{ml}$. The study [15] did however, note that a range of $0.14-41.8 \mathrm{mg} / 100$ $\mathrm{ml}$ of other acids, quinic, isocitric, shikimic, citric and fumaric acids could be found in apple tissue which would not all be measured by the TA method but would make considerable 
contributions to the tart taste of apples and juices that contain them. Unfortunately, in this study no record of the cultivar was collected, all that was recorded was that they were green eating apples. TA values express the sourness of fruits and are particularly useful in ripening studies $[16,17]$. In this study the TA values show that the juice would be pleasant to drink. Another study [18], showed that the ratio of sugar and acid in apple fruits is important to determine the taste and flavour of apples and fruit and that organically grown apples might have more favourable ratios.

One of the positive features of processing raw fruit and vegetable mixes into juice is that the juice retains a wide range of phytochemicals and antioxidants [8]. An important feature is that the juices are processed without any heating or cooking so any unstable nutrients are not lost in the juicing process. This is one of the most beneficial aspects of this process for human nutrition. Unfortunately, there is also retention of less beneficial constituents, for instance, soluble oxalates. This is a potential problem if produce with a high oxalate content is included, such as spinach leaves. These are often added to juices because of their colour and availability. Spinach leaves are known to contain high oxalate levels $[3,5,19]$, but they are traditionally cooked in water. Boiling the leaves allows significant amounts of soluble oxalate to leach into the water which considerably reduces the amount consumed [13]. Consumption of additional calcium in the juice or in the diet [20] would allow an increased conversion of soluble oxalate to its insoluble form which is not absorbed from the intestinal tract. This study shows that a high-speed blender produces a lower oxalate containing juice compared to the juice prepared by the masticating juicer However, a lower proportion of spinach leaves or any other high oxalate containing fruits or vegetables should be used to prepare healthy juices.

\section{Conclusions}

The high-speed blender produced a smoothie-like juice which retained all of the plant fibre and contained the lowest oxalate content when compared to the clear juice produced by the masticating juicer. Juicing vegetables and fruits is a positive way to increase the consumption of useful amounts of essential nutrients in the diet but if juicing becomes more popular a reduction in the amount of spinach leaves added to the juicing mixture should be made.

Acknowledgment. The authors wish to thank Dr L. Vanhanen for the supply of fruits and vegetables used in this experiment and for the oxalate analysis. The work was financially supported by the Department of Wine, Food and Molecular Biosciences, Lincoln University, Canterbury, NZ.

\section{References}

1. R. Siener, R. Honow, A. Seidler, S. Voss, H. Albrecht, Food Chem, 98 (2006)

2. T. K. Odufuwa, A. K. Atunnis, O. D. Olukanni, B. A. Salau, Int. J. Food Nutr. Sci, 3, 3 (2014)

3. S. C. Morisson, G. P. Savage, Oxalates, in Encyclopedia of Food Sciences and Nutrition $2(2003)$

4. United States Department of Agriculture (USDA), Oxalic acid content of selected vegetables. Retrieved from http://www.ars.usda.gov/Services/docs.htm?docid=9444 (2009)

5. T. S. Simpson, G. P. Savage, R. Sherlock, L. P. Vanhanen, J. Agr. Food Chem, 57 (2009)

6. United States Department of Agriculture (USDA), Oxalic acid content of selected vegetables. Retrieved from http://www.ars.usda.gov/Services/docs.htm?docid=9444 (2009) 
7. V. R. Franceschi, P. A. Nakata, Annu. Rev. Plant Biol, 56 (2005)

8. J. Zheng, Y. Zou, S. Li, P. Zhang, Int. J. Mol. Sci, 18 (2017)

9. M. J. Esteve, A. Frigola, Adv. Food Nutr. Res, 52 (2007)

10. J. Chatham, Juicing: the complete guide to juicing for weight loss, health and life (Callisto Media Inc, 2012)

11. AOAC International. Official Method of Analysis of AOAC. The Association. (Arlington.VA. USA, 1990)

12. Forage Analysis Test Procedures http://www.foragetesting.org/lab procedure /sectionB/2.2/part2.2.2.5.htm, National Forage Testing Association, (Omaha, NE, 2006)

13. L. Vanhanen, G. P. Savage, NFS Journal, 1, (2015)

14. AOAC. Official methods of analysis of the AOAC (18th ed.). (Washington, DC, USA, 2000)

15. G. P. Savage, L.S. Vanhanen, S. M. Mason, A. B. Ross, J. Food Comp. Anal, 13 (2000)

16. T. A. Eisele, S. R. Drake, J. Food Compos. Anal, 18 (2005)

17. C. Han, C. Lederer, M. McDaniel, Y. Zhao, J. Food. Sci, 70, 3 (2005)

18. T. Hernandez-Perez, A. Carrillo-Lopez, F. Guevara-Lara, A. Cruz-Hernandez, O. Paredes-Lopez, Plant Foods Hum. Nutr, 60 (2005)

19. A. Hecke, K. Herbinger, R. Veberic, M. Trobec, H. Toplak, F. Stampar, H. Keppel, D. Grill, Eur. J. Clin. Nutr, 60 (2006)

20. S. C. Noonan, G. P. Savage, Asia Pac. J. Clin. Nutr, 8 (1999) 